\title{
Article
}

Arq Neuropsiquiatr 2011;69(3):466-469

\section{Neuroimmunological findings of Angiostrongylus cantonensis meningitis in Ecuadorian patients.}

\author{
Alberto J. Dorta-Contreras ${ }^{1}$, Barbara Padilla-Docal', \\ Juan M. Moreira², Luiggi Martini Robles³, Jenny Muzzio Aroca³, \\ Fernando Alarcón ${ }^{4}$, Raisa Bu-Coifiu- Fanego ${ }^{1}$
}

\begin{abstract}
Meningitis caused by Angiostrongylus cantonensis has recently been reported in patients resulting from the first outbreaks in subtropical regions of Ecuador. Method: Eight young adult patients from the two outbreaks were studied. IgA, $\operatorname{lgM}, \lg G$ and albumin in cerebrospinal fluid and serum were quantified and plotted in cerebrospinal fluid/serum quotient diagrams (Reibergrams). The anamnesis on the patients included asking about any consumption of raw snails, symptoms and harm caused. Results: Mean eosinophilia of $7.5 \%$ and $26 \%$ in serum and cerebrospinal fluid respectively was observed, as well as a moderate increase in total proteins. The most frequent pattern of intrathecal synthesis was observed in three classes of immunoglobulins. Intrathecal synthesis of IgM was observed in all cases two weeks after the first symptoms appeared. Conclusion: The intrathecal synthesis patterns of eosinophilic meningitis due to Angiostrongylus cantonensis, facilitated by cerebrospinal fluid analysis, were similar to those of previous cases from abroad. Key words: Angiostrongylus cantonensis, Ecuador, eosinophilia, intrathecal synthesis, meningitis, Reibergram.
\end{abstract}

Hallazgos neuroinmunologicos en meningitis por Angiostrongylus cantonesis en pacientes ecuatorianos

\section{RESUMEN}

La meningitis provocada por Angiostrongylus cantonensis ha sido reportada recientemente en pacientes procedentes de los primeros brotes reportados en regiones subtropicales de Ecuador. Método: Ocho adultos jóvenes procedentes de dos brotes fueron estudiados. Se cuantificó IgA, IgM, IgG y albúmina en suero y líquido cefalorraquídeo y fueron colocados en los gráficos de las razones líquido cefalorraquídeo/suero (reibergramas). La anamnesia incluía ingestión de caracoles crudos, los síntomas y los daños provocados. Resultados: Una eosinofílica promedio de 7,5 y $26 \%$ en suero y líquido cefalorraquídeo fue observada al igual que un moderado incremento en las proteínas totales. El patrón de síntesis intratecal predominante fue de tres clases de inmunoglobulinas. La síntesis

\section{Correspondence}

Alberto Juan Dorta-Contreras Universidad de Ciencias Médicas de La Habana - Facultad de Ciencias Médicas "Dr. Miguel Enríquez", Laboratorio Central de Líquido Cefalorraquídeo (LABCEL) Ramón Pintó 212. Luyanó, 10 de Octubre - 10700 Ciudad Habana - Cuba. E-mail: adorta@infomed.sld.cu

Received 19 July 2010 Received in final form 15 March 2011 Accepted 25 March 2011 intratecal de lgM se observó en todos los casos a las dos semanas después del inicio de los síntomas. Conclusión: El patrón de síntesis intratecal de la meningitis eosinofílica por Angiostrongylus cantonensis facilitado por el análisis del líquido cefalorraquídeo fue similar a los casos previos reportados fuera del país.

Palabras-clave: Angiostrongylus cantonensis, Ecuador, eosinofilia, síntesis intratecal, meningitis, Reibergrama.

'Central Spinal Fluid Laboratory (LABCEL), "Dr. Miguel Enríquez” School of Medical Sciences, Havana University of Medical Sciences, Havana, Cuba; ${ }^{2}$ Department of Public Health Control and Improvement, Ministry of Public Health, Quito, Ecuador;

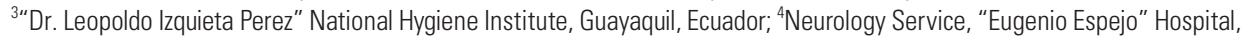
Quito, Ecuador. 
Angiostrongylus cantonensis is a zoonotic pathogen that occasionally causes human eosinophilic meningitis. Humans acquire the disease after ingesting intermediate or paratenic hosts such as terrestrial or aquatic molluscs with little or no cooking, or vegetables contaminated by infective third-stage larvae ${ }^{1}$.

Angiostrongyliasis is diagnosed on the basis of clinical manifestations, including the presence of cerebrospinal fluid (CSF) eosinophils, and a history of exposure to the larvae. The serological tests vary in sensitivity, and their availability is limited. Therefore, their clinical use is limited.

Angiostrongylus cantonensis meningoencephalitis was first reported in the western hemisphere in Cuba in $1981^{1,2}$. It has subsequently been reported in several Caribbean countries and in the United States ${ }^{3-9}$.

In Cuba, human angiostrongyliasis frequently occurs in outbreaks, with numbers of cases that may range from 8 to 100 cases $^{2}$ during rainy periods.

So far, there have not been any reports of neuroimmunological studies on the disease in South America, although the presence of the molluscs, which are intermediate hosts in the lifecycle of the parasite, has been reported in Brazil ${ }^{10,11}$, and cases of the disease have been reported in Brazil ${ }^{12,13}$ and Ecuador ${ }^{14}$.

Currently, the onset of this disease in the western hemisphere is peculiar ${ }^{15,16}$.

This paper had the aim of presenting neuroimmunological data on such patients in Ecuador ${ }^{17}$.

\section{METHOD}

\section{Patients and collection of samples}

Eight patients were studied according the infection sources. They were hospitalized at the Neurological Service of the Eugenio Espejo Hospital, Quito, between December 2008 and April 2009. The patients became infected after eating raw (uncooked) molluscs that they had either found in an uncultivated field or bought at an informal market in Quito ${ }^{17}$. The diagnosis of A. cantonensis meningitis was based on the history of eating raw molluscs, the symptoms, presence of eosinophils in cerebrospinal fluid $(\mathrm{CSF})^{18}$ and the characteristics of the outbreak, which include infected mollusks, infected rats and the presence of third-stage larvae of $A$. cantonensis in CSF and brain tissue from the outbreak index case who died ${ }^{17}$.

The research was approved by the Research Bioethics Committee of Eugenio Espejo Hospital. All the patients gave their informed consent for a diagnostic lumbar puncture procedure to be performed and for their clinical data history to be used.

Simultaneous samples of serum and CSF were collected in order to perform the neuroimmunological analysis. These samples were collected seven days after the onset of the symptoms and small quantities were kept at $-80^{\circ} \mathrm{C}$ until the time of their use.

\section{CSF and serum analysis}

The levels of the major immunoglobulins in serum were measured by means of radial immunodiffusion in NOR Partigen ${ }^{\odot}$ plates (Siemens, Marburg) and in CSF using LC Partigen plates (also from Siemens).

Serum albumin was quantified by means of radial immunodiffusion plates in NOR Partigen and albumin in CSF, in LC Partigen ${ }^{\oplus}$ plates (Siemens, Marburg) in order to determine whether there was any intrathecal synthesis of immunoglobulins and to ascertain the situation of the blood-CSF barrier.

Both the immunoglobulin and the albumin concentration in quotient CSF/serum form were plotted in a Reibergram, which is a CSF/serum quotient diagram for major immunoglobulin classes ${ }^{18,19}$.

\section{RESULTS}

The eight patients reported in these outbreaks were young adults and belonged to two different families with an average age of 23 years that simultaneously became sick. Headache, vomiting, diarrhea, neck stiffness and severe radicular pain were the most common clinical manifestations, and they started one to two weeks after eating raw molluscs. Two cases showed severe consciousness deficits and one of these entered into a coma. No seizures were reported; imaging findings were negative; and there was no skin damage.

Mean eosinophilia of $7.5 \%$ and $26 \%$ respectively was observed in the serum and in CSF (Table 1). A moderate increase in proteins was observed in all cases. Glucose levels were normal. The CSF samples from each patient were stained using the Gram stain and the results were negative. The BAAR test, China ink test and microbiological cultures were all negative for the eight patients.

The exclusion criteria that aimed to eliminate other possible causes of angiostrongyliasis included any histories of raw fish consumption, histories of migratory swelling, clinical diagnoses of subarachnoid hemorrhage or myeloencephalitis, positive serological tests for gnathostomiasis or cysticercosis, abnormal brain computed tomography or magnetic resonance findings, symptomatic or serologically positive HIV infection, and active or previous histories of tuberculosis or malignancy. Thus, neurocysticercosis, paragonimiasis, echinococcosis, gnathostomiasis, neurotuberculosis, neuroaids and neurococcidioides were discarded.

Table 2 shows the patterns of intrathecal synthesis of major immunoglobulins with their frequencies of appearance per patient. Pattern I was found to be the most frequent type. 
Table 1. Laboratory tests on Ecuadorian patients suffering from A. cantonensis meningitis.

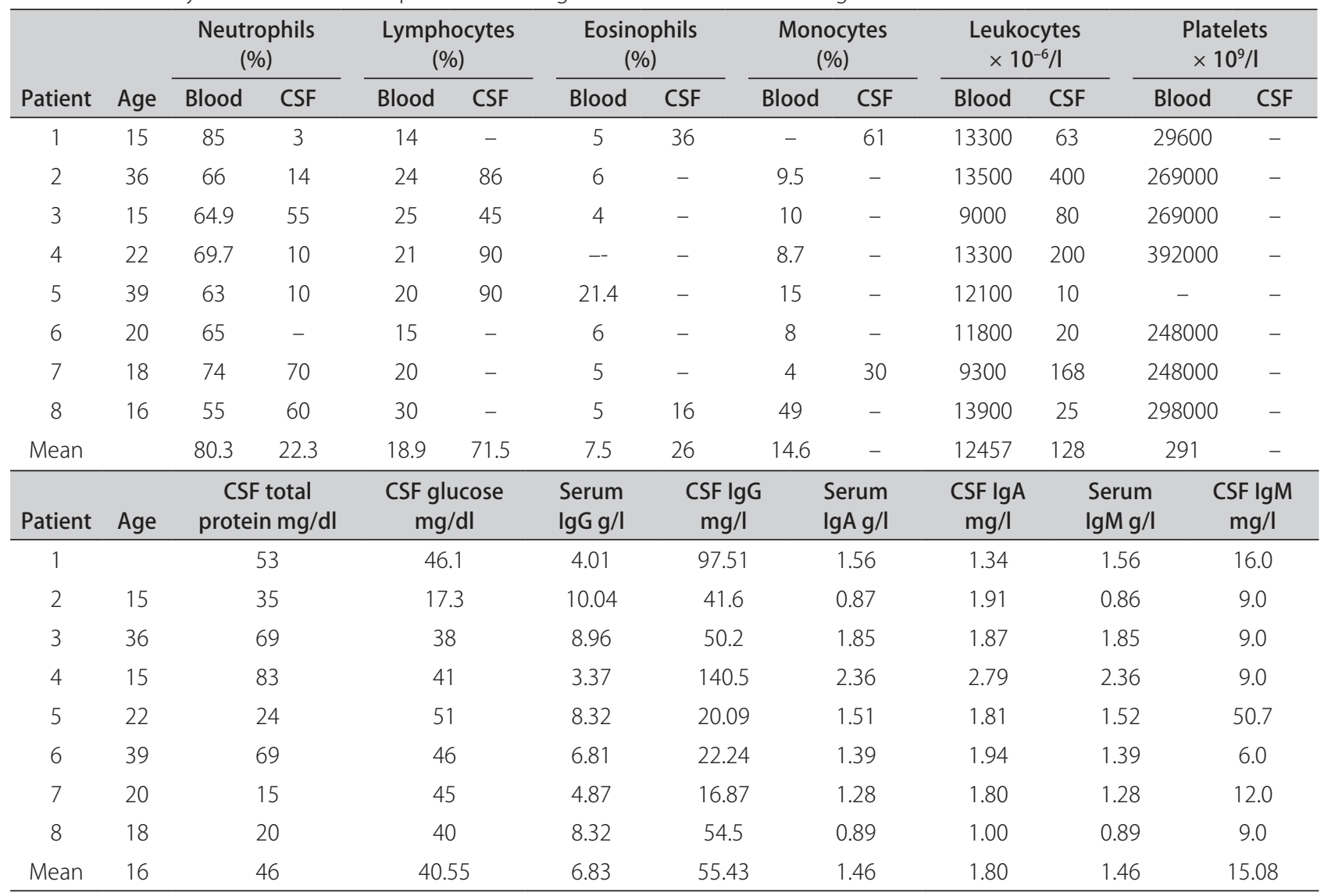

Figure shows the Reibergram for major classes of immunoglobulins. All the patients showed intrathecal synthesis of at least two classes of immunoglobulins and all showed intrathecal synthesis of IgM. A three- immunoglobulin intrathecal synthesis pattern is the most frequent one.

\section{DISCUSSION}

In Ecuador, it is very common to eat raw molluscs. They are mostly prepared as seviche, which is a spiced dish of raw fish or molluscs marinated in lemon juice, salt and onion. There had never been any reports of transmission of $A$. cantonensis in Ecuador up to mid2008. However, several cases of meningoencephalitis in Los Rios and Guayas provinces were then found and, in one of them, the presence of an L5 larva in the subarachnoid space of a dead patient confirmed that the disease was presence and was being transmitted in Ecuador ${ }^{14,17}$, with a large parasite load. From that moment on, every outbreak of eosinophilic meningoencephalitis with antecedents of consumption of raw molluscs came to be considered related to A. cantonensis.

Most mollusc species are sensitive and able to transmit the disease. Terrestrial and aquatic molluscs are the primary intermediate hosts ${ }^{17}$. In certain Ecua-
Table 2. Patterns of intrathecal synthesis of immunoglobulins in Ecuadorian patients suffering from $A$. cantonensis meningitis.

\begin{tabular}{ccc}
\hline No. & Patterns of synthesis & Frequency \\
\hline I & $\lg \mathrm{A}+\lg \mathrm{M}+\lg \mathrm{G}$ & $5 / 8$ \\
II & $\lg M$ & $2 / 8$ \\
III & $\lg \mathrm{A}+\lg M$ & $1 / 8$ \\
\hline
\end{tabular}

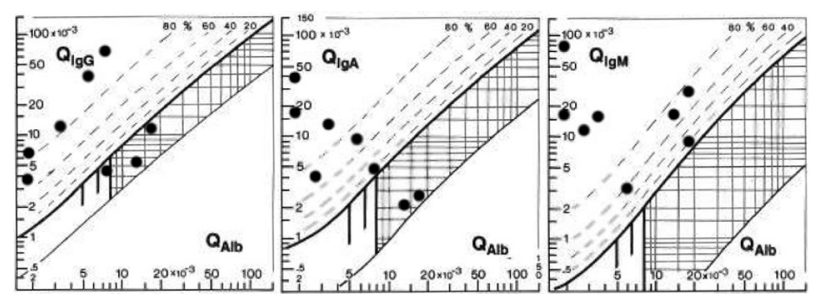

Figure. Reibergrams or Reiber's ratio graphs of Ecuadorian patients suffering from A. cantonensis eosinophilic meningoencephalitis. Note that three patients have Qalb values higher than $7 \times 10^{-3}$, which shows dysfunction of the blood-CSF barrier. This situation corresponds to the time when the samples were taken, which did not coincide with the acute phase of the disease. In addition, the graphs shown that the patients who maintained functional integrity of the blood-CSF barrier had intrathecal synthesis of $\lg G$ and $\lg A$, while all the patients synthesized $\operatorname{lgM}$, because they are plotted above the strongest hyperbolic line, which marks the limit between intrathecal synthesis and normal diffusion through the barrier. 
dorian regions, one or two species are intermediate hosts and the infection intensity is very high. The existence of Achatina fulica has been reported in Brazil, and in other countries in South America, which makes it possible for this nematode to be present in the Ecuadorian regions ${ }^{10,11}$, with reported cases ${ }^{12,13}$. This invertebrate has also been found in large populations in all the places where the disease was reported after the first outbreak ${ }^{17}$.

Mollusc species infected with the infective larvae of A. cantonensis were found in Los Rios in Vaginulus sp., Pomacea lineata, Pomacea sp. and Achatina fulica. Regarding the definitive hosts for this parasite, it was found that predominant species infected by the nematode were Rattus rattus and Rattus norvegicus ${ }^{14,17}$.

It is thought that $A$. cantonensis has only recently been introduced into Ecuador and that it was probably caused by infected rats from ships or infected snails.

There were no fatal cases among the eight patients studied, although two of them showed severely impaired consciousness and one of them entered into a coma. However, considering all the notified outbreaks in Ecuador, a total of 26 patients have been diagnosed over a one-year period, of whom eight had neurological sequelae and two died ${ }^{14,17}$.

The aggressiveness of the illness when large quantities of third-stage larvae of the parasite are eaten is commonly observed in China, Thailand and other countries in southeastern Asia that have similar nutritional habits ${ }^{20,21}$. These sequelae have not been observed in Cuban patients because larva ingestion is purely accidental ${ }^{22}$.

Dysfunction of the blood-CSF barrier was not a distinctive sign in the patients of this study, since only $37 \%$ of the patients involved presented dysfunction of the barrier. This matches with observations from studies in which a second lumbar puncture was performed on patients eight days after the onset of symptoms ${ }^{22-24}$.

The observation of the patterns of intrathecal synthesis of immunoglobulins in these Ecuadorian patients is interesting because IgM was present in all of them.

The reported percentage of IgM in Cuban patients was $86 \% 22$, while in Ecuadorians it was $100 \%$, but with a $5 \%$ general lethality rate (taking the eight patients of the present report into account) and a sequela rate of $22.5 \%{ }^{14,16}$.

It is likely that infestation caused by A. cantonensis may shortly be reported in other Latin American countries like Peru and Colombia, which share similar habitats and culinary customs. For this reason, the observations of the present study may be of use for the sanitary authorities when dealing with epidemic outbreaks similar to the ones in Ecuador.

These neuroimmunological findings provide further information about the immune response of eosinophilic meningitis caused by $A$. cantonensis, which is currently a disease that is spreading through South America.

\section{REFERENCES}

1. Aguiar PH, Morera P, Pascual J. First record of Angiostrongylus cantonensis in Cuba. Am J Trop Med Hyg 1981;30:963-965.

2. Dorta-Contreras AJ. Meningoencefalitis eosinofílica en Cuba. Rev Neurol 2001;32:999-1000.

3. Raccurt C, Balaise J, Durette-Desset MC. Présence d'Angiostrongylus cantonensis en Haïti. Trop Med Intern Health 2003;8:423-426.

4. Anderson E, Gubler DJ, Sorensen K, Beddard J, Ash LR. First report of Angiostrongylus cantonensis in Puerto Rico. Am J Trop Med Hyg 1986; 35:319-322.

5. Lindo JF, Waugh C, Hall J, et al. Enzootic Angiostrongylus cantonensis in rat and snails after an outbreak of human eosinophilic meningitis, Jamaica. Emerg Infect Dis 2002;8:324-326.

6. Vargas M, Gómez-Pérez JD, Malek EA. First record of A. cantonensis (Chen, 1935). Nematode: metastrongyloidae in the Dominican Republic. Trop Med Parasitol 1992;43:253-255.

7. Chikweto A, Bhaiyat MI, Macpherson CNL, et al. Existence of Angiostrongylus cantonensis in rats (Rattus norvegicus) in Grenada, West Indies. Veterinary Parasitology 2009;162:160-162.

8. Campbell BG, Little MD. The finding of Angiostrongylus cantonensis in rats in New Orleans. Am J Trop Med Hyg 1988;38:568-573.

9. Hochberg NS, Park SY, Blackburn BG, et al. Distribution of eosinophilic meningitis cases attributable to Angiostrongylus cantonensis, Hawaii. Emerg Infect Dis 2007;13:1675-1680.

10. Caldeira Rl, Mendonça CLGF, Goveia CO, et al. First record of molluscs naturally infected with Angiostrongylus cantonensis (Chen, 1935) (Nematoda: Metastrongylidae) in Brazil. Mem Inst Oswaldo Cruz 2007;102:887-889.

11. Graeff-Teixeira C. Expansion of Achatina fulica in Brazil and potential increased risk for angiostrongyliasis. Trans R Soc Trop Med Hyg 2007;101: 743-744.

12. García MH, Moraes C, Almada Gl, et al. First reported outbreak of eosinophilic meningitis caused by Angiostrongylus cantonensis in Brazil. International Conference on Emerging Infectious Diseases 2008. Available in: http:// www.cdc.gov/eid/content/14/3/ICEID2008.pdf (reviewed 23/10/2009).

13. Melo Correa Lima AR, Dornelas Mesquita S, Sobreira Santos S, et al. Alicata disease: neuroinfestation by Angiostrongylus cantonensis in Recife, Pernambuco, Brazil Arq Neuropsiquiatr 2009;67:1093-1096.

14. Pincay T, García L, Narváez E, et al. Angiostrongiliasis due to Parastrongylus (Angiostrongylus) cantonensis in Ecuador: first report in South America. Trop Med Internat Health 2009;14(Suppl 2):S37.

15. Dorta Contreras AJ, Magraner Tarrau ME, Sánchez Zulueta E. Angiostrongyliasis in the Americas. Emerg Infect Dis 2009;15:991.

16. Dorta Contreras AJ, Núñez Fernández FA, Pérez Martín O, et al. Peculiaridades de la meningoencefalitis por Angiostrongylus cantonensis en América. Rev Neurol 2007;45:755-763.

17. Pincay T, Garcia L, Decker O, et al. Angiostrongiliasis por Parastrongylus (Angiostrongylus) cantonensis en Ecuador. Bol Epid (Ecu) 2009;6:25-32.

18. Reiber H. Flow rate of cerebrospinal fluid (CSF): a concept common to normal blood-CSF barrier function and to dysfunction in neurological diseases. J Neurol Sci 1994;122:189-203.

19. Reiber $\mathrm{H}$. The hyperbolic function: a mathematical solution of the protein flux/CSF flow model for blood-CSF barrier function. J Neurol Sci1994; 126: 243-245.

20. Wang $Q P$, Lai $D H$, Zhu $X Q$, et al. Human angiostrongyliasis. Lancet Infect Dis 2008:8:621-630.

21. Wang J, Qi H, Diao Z, et al. An outbreak of Angiostrongyliasis cantonensis in Beijing. J Parasitol 2010;96:377-381.

22. Dorta Contreras AJ, Reiber H. Intrathecal synthesis of immunoglobulins in eosinophilic meningoencephalitis due to Angiostrongylus cantonensis. Clin Diagn Lab Immunol 1998;5:452-455.

23. Tsai HC, Chung LY, Chen ER, et al Association of matrix metalloproteinase- 9 and tissue inhibitors of metalloproteinase- 4 in cerebrospinal fluid with blood-brain barrier dysfunction in patients with eosinophilic meningitis caused by Angiostrongylus cantonensis. Am J Trop Med Hyg 2008:78:20-27.

24. Wang $Q P$, Lai $D H$, Zhu $X Q$, et al. Human angiostrongyliasis. Lancet Infect Dis 2008:8:621-630. 